\title{
Study on the current situation and Countermeasures of new vocational farmers Cultivation -- An Empirical Analysis Based on Xiaogan city of Hubei Province
}

\author{
Tong Lei \\ College of Technology, HuBei Engineering University, Xiaogan, China, 432000
}

Keywords: new type of professional farmers; training status; countermeasures analysis; Hubei Xiaogan

\begin{abstract}
With the development of the times and social progress, our country's first industry is gradually developed, and its main labor force, farmers are also urgent need for new professional training. Effective foster new occupation of farmers can not only protect our national food safety stock, and also to ensure national agricultural products mainly for supply and development of the society, the development of agricultural modernization through effective means, to ensure the long-term development of agriculture. Through the new occupation farmer training course in Hubei province can know, effectively solve the present rural peasant farming in how farming can yield, who farming and farming to these problems, and to present results need to publicize the new occupation farmer management and training, to further increase the new occupation farmer training frequency and the number of training, the training is strengthened.
\end{abstract}

\section{Introduction}

Through the investigation and analysis of research for many years, whether in our country or foreign experts for the new occupation of farmers' cultivation and management have carried out extensive research and analysis, the main research is divided into the following areas. First, the main real research is about the peasants, the biggest difference between which is the difference between the traditional peasants and the new professional peasants. Relevant experts in the state believe that professional farmers and traditional farmers have some differences and relations. Pointed out that the past farmers, that is, the traditional farmers, the main purpose of farming is to better life, to protect basic living conditions, and is able to correspond with the identity of a group of people. But the occupation of farmers at this stage is to effectively carry out an identity management market, the farmer's crops and business activities as a commodity industry, and can effectively use all possible industrial reward maximization application [1].

\section{New vocational farmers cultivate the status quo}

Through the combination of the upgrading and evolution of the peasants' Professionalization in China at present stage, the experts in the relevant fields of agricultural cultivation have effectively put forward four important characteristics that farmers should possess. First of all, the farmers should be full occupation duty of agriculture, should possess higher occupation quality and personal quality, should be reasonable to obtain the higher income, occupation of farmers should be able to get the respect of the community. Secondly, at this stage to ensure our country's food safety can be in the range of effective, should be a lot of new occupation farmer training, improve the relationship between food security and the new occupation farmer. Secondly, the relationship between vocational training and the new type of professional farmers. Relevant experts in the field of our country, the large number of new farmers' occupation training is effective in our country are found in agricultural modernization and important requirements of the implementation of comprehensive construction of new socialist countryside, can be an important means to ensure the goals and tasks of our country occupation farmer training science, and should follow the development track of our country in a certain occupation of farmers the extent and the development of the law. Finally, the modernization of agriculture and the development of new types of professional farmers. Relevant 
experts in the field of our country that is the occupation of new farmers to improve the farmers' quality and improving the living standards of farmers, agricultural modernization is the most important force in our country, effective guarantee of providing high-quality personnel of new occupation in China for farmers and agricultural development can be better for the modernization of the. Some experts also suggested that we should establish a certain system of professional farmers' registration and effectively train the main agricultural forces who can engage in modernization. The most important is, combined with the new occupation farmer in China should and specific environment, to ensure a good relationship, so that farmers can get a reasonable land use, land use rights to ensure reasonable arrangements, so that farmers fully respected in society, to form a good agricultural environment and atmosphere [2].

At this stage, both domestic and foreign, the relevant research experts are still in the initial stage for the cultivation of new type of professional farmers. Some of the results of the study show that the new occupation farmer there were some problems in the whole process of the system, the lack of comprehensive combing their summary, to the new occupation farmer training and related research measures are also lack of exploration and research. Therefore, we should further study the cultivation of new type of professional farmers should be more necessary. At present, with the progress of the times, many large outflow of rural labor in Hunan province Xiaogan City, there are some agricultural variation phenomenon, and the emergence of the phenomenon of aging in rural areas, rice planting area has a shrinking, will gradually appear some problems of land abandonment. In order to solve this problem better, it is necessary to study and analyze some related culture and technology to ensure the formation of new professional farmers [3].

\section{The significance of cultivating new type of professional peasant team}

At present our country refers to a new occupation farmer is mainly refers to the main body to carry out some basic agricultural production behavior, and as a source of livelihood of the people, also have some high cultural quality and professional skills, can carry out related business activities and management ability, also can ensure that the new farmers own high income and social respect. With China's economic development and social progress, the level of industrialization has greatly improved, the speed of urbanization is gradually accelerated, China's Xiaogan City, Hunan Province, towns and villages gradually emerged a large number of young labor from rural to urban shift, making the most of the rural labor force in Xiaogan city cultural quality level lower the age structure of the aging trend seriously, and agriculture is the gradual emergence of the alienation situation. Under such circumstances, China has successively raised a series of related opinions on the vitality of modern agricultural development. Among them, it is pointed out that our country needs to train new type of professional farmers and modern agricultural cultivation level, and further educate and train the peasants' professionalization.

With the development of the national economy and the improvement of the industrial level of our country in the proportion of food and agricultural products on the net primary productivity increases gradually, and the emergence of self-sufficiency and self-sufficient part of traditional agricultural production can not be satisfied. In the development of new type of professional peasant team, due to the influence of some natural resources, people simply rely on the traditional way of development, and the development of agriculture is very limited. Effective to speed up the construction of a new occupation farmer team, can effectively improve and promote farmers' occupation of production and management, to a certain extent to the development of intensive agriculture, improve agricultural production efficiency and commercial efficiency, we can solve the relevant national food and agricultural products from the output fundamental supply [4].

At this stage, due to the development of national economy and social improvement of living standards, some traditional agricultural management means of development gradually to the development of agriculture modernization transformation, the level of agricultural science and technology and a large number of advanced and equipped with high-tech agricultural production technology and equipment, modern agriculture and business development ideas are growing in a certain extent increasingly being applied to agricultural planting. Through the effective 
improvement of agricultural facilities and agricultural modernization of technology, to further accelerate the construction of a new occupation farmer team, can not only improve the quality of our country farmer occupation occupation scale of agricultural production and management, but also can effectively improve the production and management ability, and promote the modernization of our country agriculture production system of agriculture and farmers' occupation the quick formation to a certain extent, and promote and enhance the speed of development and the situation of modern agriculture in a certain extent.

Training new type of professional peasant team can guarantee the development of agriculture in the future. To better help the agricultural development in the future is the focus of research in our country and even the whole world, experts in the world related fields have developed a series of effective promotion to the development of farmers of agricultural and rural development strategy. Hunan city of Xiaogan Province in the industrialization and urbanization in the development process, many rural areas have suffered serious hollowing out of agriculture and alienation, and rural areas have gradually left behind elderly appeared the problem of aging. In many rural areas, the labor force generally appears out of the rural areas and runs to the cities, and leads to a great deal of idle land in rural areas. Effective to speed up the construction of a new occupation farmer team, to ensure the development of China's occupation of the peasants, and toward the environment and the system and policy and other aspects of development, but also can more realize our country agriculture problems [5].

\section{The Countermeasures of cultivating new type of professional farmers in Hunan and Xiaogan provinces}

Hunan Xiaogan area under the state vigorously appeal, the implementation of the policy of training the new occupation farmer height, through research and analysis and exploration for many years, the analysis and Research on the technology of the occupation of farmers.

At this stage, according to Xiaogan's modern agriculture development plan and related agricultural modernization production situation analysis, according to the country to promote the overall planning, the combination of planting and breeding principles, selection of operation and management of some important industrial pilot industry. Separately from some production scale, as well as the scientific and technological content, as well as the economic efficiency, the service level, carries on the confirmation to some new type professional farmers, establishes a set of dynamic management pattern. Since our country promulgated the corresponding administrative departments to identify the main document, we should gradually according to some industry scale and agricultural ability to identify the standard formulation. According to the analysis of some way below, respectively select multiple training objects from Xiaogan to various towns and rural areas, the final choice with some standards that farmers need to identify and pilot training, some new occupation farmer, effectively carry out comprehensive skills training and entrepreneurship training.

Cultivate new type of professional farmers according to the level. At the present stage our country has clearly formulated for occupation types of farmers, and effectively relying on the Xiaogan City area of rural labor resources for the sunshine project training must ensure, to make some special layered West technical training for new farmers, can be classified according to the level of technical level of peasants, and to ensure a certain occupation and agricultural technology combined to ensure that farmers can according to a certain expert or title assessment skills for farmer expert. In addition, it should also be farmers' entrepreneurial intention in the context of the collection activities, to ensure the new occupation farmer ideas and opinions can be effectively applied to the modernization of agricultural production process in the future, inject some vitality to the city of Xiaogan in the future development of modern agricultural production. At present our city to build a new occupation farmer training system has been basically established, and training more than some new occupation farmer 1000, and selected more than 50 people to accept some of the training system of agriculture. And in these new professional farmers, more than 10 people have achieved higher education. Through the scientific and rational training and study of the urban and rural farmers in Xiaogan, we can ensure that farmers and technical personnel in the city can 
effectively integrate with the new type of professional farmers. In the cultivation of farmers, through the guidance of the site and establish a certain information platform, effectively solve the difficulties of farmers in the process of farm work. In addition, but also through establishing some technical, and ensure that we test some new varieties of demonstration rocks, to ensure the organization of new farmers' learning, and cultivate some future benefits for the development of agricultural talents.

According to the industry category to stimulate new professional farmers farmers, the government effectively plays some positive role through policy introduced, approaches to help policy object and policy specific clearly in a certain extent, and should operate in accordance with the operation process, ensure the new occupation farmer can the agricultural business itself. In support of the type can be divided into the project support, financial support, support from the support and support from the construction and so on [6].

\section{The main achievements of the cultivation of new type of professional farmers in Hunan and Xiaogan}

Cultivate a number of scientific and technological demonstration households Xiaogan City, the level of agricultural science and technology to some extent improve the peasants, and related policies and support, effectively improve the overall quality of the new occupation farmer in agricultural production, to a certain extent, improve farmers' Entrepreneurship and employment ability, further reducing the risk of unemployment, effective to promote the healthy development of the modernization of the new occupation farmer team. There are a large number of rice planting families in Xiaogan, and some vegetables and large farmers, all of which can lead the development of agricultural professionalism in Xiaogan to a certain extent. 5.2Promoted the large-scale production of grain

Through the production efficiency and production technology training of the new type of professional farmers, Xiaogan has effectively promoted the scale and standardization of the planting of some crops in Xiaogan. Among them, the new type of professional farmers can grow more and more rice, and be able to actively promote the work, under the joint efforts of everyone, the contracted land can be fully planted.

\section{Conclusion}

In view of the above, we can put forward some opinions on the cultivation of new type of professional farmers in Hunan District of Xiaogan province at the present stage. First, effectively strengthen the management of new professional farmers. Ensure the operation according to the state regulations, and establish an effective information database and information management system. Second, to further increase the cultivation of new professional farmers. Improve the relationship between the various sectors of agriculture, improve the efficiency of the entire agricultural project. Third, we should increase the policy support of new type of professional peasants. Fourth, to further promote the effectiveness of the cultivation of new professional farmers. I believe that through this study and analysis, it can help the study of the cultivation of new farmers in Hubei, Xiaogan province.

\section{Acknowledgment}

Fund program: Scientific Research Fund of Hu Bei Engineering University (201544)

The first author: Tong Lei, Male, Danjiangkou, HuBei province, August, 1985.

Master degree, Lecturer, Business Management

\section{References}

[1] Han J. On the Current Situation and Countermeasures of the Reserve Talents' Cultivation in 
CBA[J]. Journal of Pla Institute of Physical Education, 2006.

[2] Feng Q M. On the Current Situation and Countermeasures of the Competitive Sports Reserve Talents' Cultivation in China[J]. Journal of Pla Institute of Physical Education, 2006.

[3] Zhang G. Analysis on the Current Situation of the Competitive Sports-talents' Cultivation in Universities and its countermeasures[J]. Journal of Guangdong Polytechnic Normal University, 2009.

[4] Weng C, Yan R. Situation Analysis and Countermeasure Study on Rural Vocational Education and Training for Modern Farmers' Cultivation Based on Information Technology[C]// International Conference on Computer Science, Environment, Ecoinformatics, and Education. Springer Berlin Heidelberg, 2011:76-80.

[5] Yue W J, Fang H H, Jin H U. Study on current situation and countermeasures of students' comprehensive quality cultivation in higher vocational colleges[J]. Journal of Anhui Technical College of Water Resources \& Hydroelectric Power, 2014.

[6] Chen J P, Zhao C X, University D O. Research on the Present Situation and Countermeasures of Information Technology in the Cultivation of New-type Professional Farmers' Quality[J]. Times Agricultural Machinery, 2017. 